in nature, I predict that mice with no heparan sulfate activity will develop thrombosis, supporting the concept that heparan sulfate is antithrombotic. These mice also should exhibit more profound intrauterine growth retardation than 3-OST-1 knockouts (15), thereby demonstrating a biological gradient for this unexpected finding depending on the extent to which heparan sulfate activity is reduced.

\section{Summary}

With their studies in 3-OST-1 knockout mice, HajMohammadi and colleagues (15) have advanced our understanding of the pathways that regulate thrombin. Antithrombin is critical for thrombin regulation because even partial deficiency is associated with thrombosis. In contrast, complete deficiency of heparan sulfate activity is necessary to provoke thrombosis. These findings suggest that small amounts of residual heparan sulfate activity are sufficient to catalyze antithrombin or that other vessel wall glycosaminoglycans can compensate for all but complete lack of heparan sulfate activity.

\section{Acknowledgments}

J.I. Weitz is the recipient of a Career Investigator Award from the Heart and Stroke Foundation of Ontario and holds the Heart and Stroke Foun- dation of Ontario/J. Fraser Mustard Chair in Cardiovascular Research, and the Canada Research Chair in Thrombosis at McMaster University.

1. Mann, K.G., Butenas, S., and Brummel, K. 2003. The dynamics of thrombin formation. Arterioscler. Thromb. Vasc. Biol. 23:17-25.

2. Esmon, C.T., et al. 1997. The protein C pathway: new insights. Thromb. Haemost. 78:70-74.

3. Healy, A.M., Rayburn, H.B., Rosenberg, R.D., and Weiler, H. 1995. Absence of the blood-clotting regulator thrombomodulin causes embryonic lethal ity in mice before development of a functional cardiovascular system. Proc. Natl. Acad. Sci. U. S. A. 92:850-854

4. Isermann, B., et al. 2001. Endothelium-specific loss of murine thrombomodulin disrupts the protein $\mathrm{C}$ anticoagulant pathway and causes juvenileonset thrombosis. J. Clin. Invest. 108:537-546. doi:10.1172/JCI200113077.

5. Thomas, D.P., and Roberts, H.R. 1997. Hypercoagulability in venous and arterial thrombosis. Ann. Intern. Med. 126:638-644.

6. van Boven, H.H., and Lane, D.A. 1997. Antithrombin and its inherited deficiency states. Semin. Hematol. 34:188-204.

7. Ishiguro, K., et al. 2000. Complete antithrombin deficiency in mice results in embryonic lethality. J. Clin. Invest. 106:873-878.

8. Atha, D.H., Lormeau, J.C., Petitou, M., Rosenberg, R.D., and Choay, J. 1987. Contribution of 3-Oand 6-O-sulfated glucosamine residues in the heparin-induced conformational change in antithrombin III. Biochemistry. 26:6454-6461.

9. Forsberg, E., et al. 1999. Abnormal mast cells in mice deficient in a heparin-synthesizing enzyme. Nature. 400:773-776

10. Humphries, D.E., et al. 1999. Heparin is essential for the storage of specific granule proteases in mast cells. Nature. 400:769-772.

11. Hallgren, J., Spillmann, D., and Pejler, G. 2001. Structural requirements and mechanism of heparin-induced activation of a recombinant mouse mast cell tryptase, mouse mast cell pro- tease-6: formation of active tryptase monomers in the presence of low molecular weight heparin. J. Biol. Chem. 276:42774-42781.

12. Marcum, J.A., et. al. 1986. Cloned bovine aortic endothelial cells synthesize anticoagulantly active heparan sulfate proteoglycan. J. Biol. Chem. 261:7507-7517.

13. de Agostini, A.I., Watkins, S.C., Slayter, H.S., Youssoufian, H., and Rosenberg, R.D. 1990. Localization of anticoagulantly active heparan sulfate proteoglycans in vascular endothelium: antithrombin binding on cultured endothelial cells and perfused rat aorta. J. Cell. Biol. 111:1293-1304.

14. Kobayashi, M., Shimada, K., and Ozawa, T. 1990 Human recombinant interleukin-1 beta- and tumor necrosis factor alpha-mediated suppression of heparin-like compounds on cultured porcine aortic endothelial cells. J. Cell. Physiol. 144:383-390.

15. HajMohammadi, S., et al. 2003. Normal levels of anticoagulant heparan sulfate are not essential for normal hemostasis. J. Clin. Invest. 111:989-999. doi:10.1172/JCI200315809.

16. Nawa, K., et al. 1990. Presence and function of chondroitin-4-sulfate on recombinant human soluble thrombomodulin. Biochem. Biophys. Res. Commun. 171:729-737.

17. Koyama, T., et al. 1991. Different glycoforms of human thrombomodulin. Their glycosaminoglycan-dependent modulatory effects on thrombin inactivation by heparin cofactor II and antithrombin III. Eur. J. Biochem. 198:56-70.

18. Koide, T., Odani, S., Takahashi, K., Ono, T., and Sakuragawa, N. 1984. Antithrombin III Toyama: replacement of arginine- 47 by cysteine in hereditary abnormal antithrombin III that lacks heparin-binding ability. Proc. Natl. Acad. Sci. U. S. A. 81:289-293.

19. Boyer, C., Wolf, M., Vedrenne, J., Meyer, D., and Larrieu, M.J. 1986. Homozygous variant of antithrombin III: AT III Fontainbleau. Thromb. Haemost. 56:18-22.

20. Dewerchin, M., et al. 2000. Life-threatening thrombosis in mice with targeted Arg 47 to Cys mutation of the heparin binding domain of antithrombin. Circulation. 104:351 (Abstr.).

\title{
Transplacental thyroxine and fetal brain development
}

\section{R. Thomas Zoeller}

Department of Biology, University of Massachusetts-Amherst, Morrill Science Center, Amherst, Massachusetts, USA

J. Clin. Invest. 111:954-957 (2003). doi:10.1172/JCI200318236.

Address correspondence to: $\mathrm{R}$. Thomas Zoeller, Department of Biology, University of Massachusetts-Amherst, Morrill Science Center, Amherst, Massachusetts 01003, USA. Phone: (413) 545-2088; Fax: (413) 545-3243;

E-mail: tzoeller@bio.umass.edu.

Conflict of interest: The author has declared that no conflict of interest exists.

Nonstandard abbreviations used: congenital hypothyroidism $(\mathrm{CH})$; intelligence quotient (IQ); thyroxine (T4); triiodothyronine (T3); disabled homolog 1 (Dab1).
We all know that thyroid hormone is essential for normal brain development, so it is perhaps not surprising to read the title of the report by Lavado-Autric et al. in this issue of the JCI (1), indicating that thyroid hormone affects brain development in the rat. However, the article addresses two matters that are central to an ongoing debate about important details of thyroid hormone action in the developing brain.

Lavado-Autric et al. (1) report that subtle insufficiency of thyroid hormone in the pregnant rat disrupts the migration of neurons in the fetal cortex and hippocampus, leading to the presence of neurons in aberrant locations of the adult offspring's brain and "blurring" cortical layers. Thus, the two important issues addressed in the design of this work are the timing of thyroid hormone action in the developing brain and the relative sensitivity of the fetal brain to maternal thyroid hormone insufficiency. Considering that maternal hypothyroxinemia may be 150-200 times more prevalent than congenital hypothyroidism $(\mathrm{CH})$, several authors have recently speculated that screening for thyroid function should be routine for women early in their pregnancy 


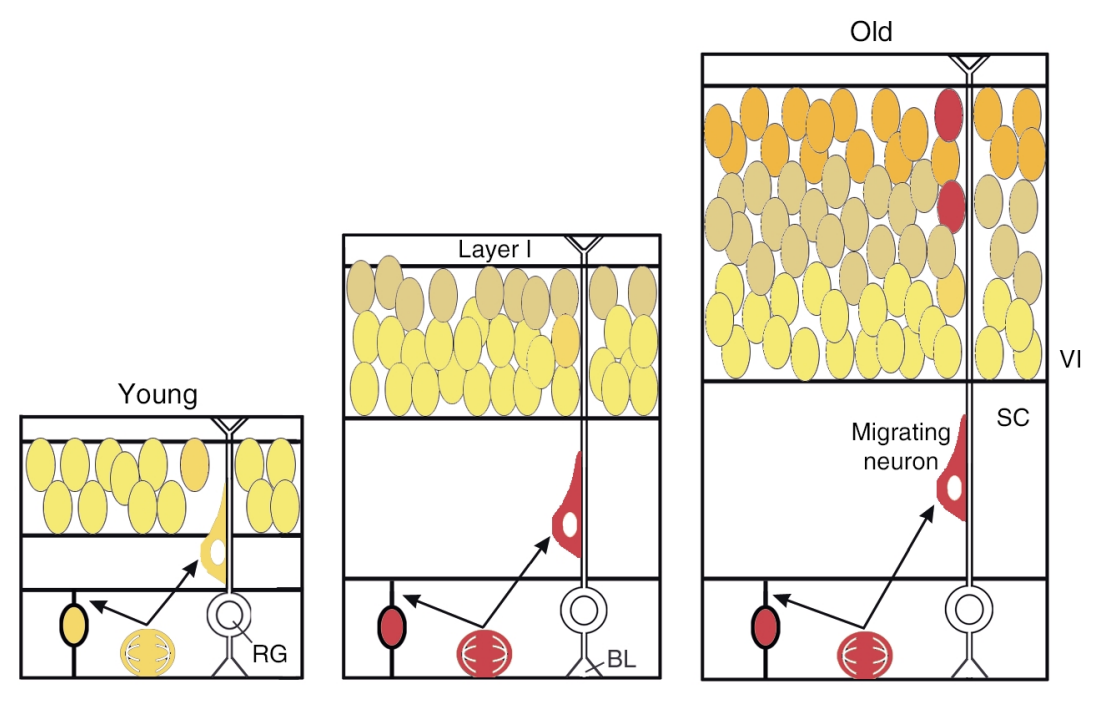

Figure 1

The "inside-out" gradient of cortical lamina is established by neurons migrating farther as development proceeds. Late-born neurons migrate past early-born neurons, forming six layers. Cortical neurons migrate along scaffolds established by radial glia, which are attached to the basal lamina of the ventricular zone and extend through to layer I. Cajal-Retzius neurons in layer I are the first neurons to populate the mantle of the cortex, and they produce and secrete Reelin, which is involved in terminating migration of neurons as they climb the scaffold. The article by LavadoAutric et al. (1) indicates that thyroid hormone plays a role in the process of neuronal migration. Specifically, rats born to dams with moderately low thyroid hormone have "blurred" cortical lamina, and many neurons do not migrate to their normal destination. Moreover, the action of thyroid hormone in this migration occurs during fetal development. The authors employed this system to show that maternal hypothyroxinemia can produce specific abnormalities in the cytoarchitecture of the cortex during fetal brain development. RG, radial glia; SC, subcortical white matter; BL, basal lamina; VI, layer VI. Adapted with permission from ref. 21.

(2) or for nonpregnant women of reproductive age.

\section{Timing of thyroid hormone action in the developing brain}

Historically, clinical and experimental work has focused on the role of thyroid hormone in postnatal brain development. This work led to the institution of mandatory neonatal screening to rapidly identify and treat infants with $\mathrm{CH}$ (3), which occurs at a rate of approximately one in 3,000-4,000 live births. Because $\mathrm{CH}$ is difficult to diagnose on the basis of clinical symptoms alone, this screening program can prevent severe neurological deficits. For example, one analysis found that the percentage of $\mathrm{CH}$ infants with an intelligent quotient (IQ) above 85 was $78 \%$ when the diagnosis was made within 3 months of birth, 19\% when it was made between 3 and 6 months, and $0 \%$ when it was made after 7 months of age (3). To understand the mechanism by which severe thyroid hormone insufficiency produces brain damage in untreated CH infants, a large body of experimental literature has focused on the role of thyroid hormone on the postnatal rodent brain (4).

The importance of thyroid hormone to fetal brain development has taken longer, and has been experimentally more difficult, to recognize. Early work suggested that thyroid hormone is not transferred from the mother to the fetus; this suggestion was based largely on the observations that human placenta and fetal membranes contain high levels of tyrosyl ring deiodinases that would degrade thyroid hormones and prevent such transfer $(5,6)$. However, Vulsma et al. reported in 1989 that newborns with a genetic incapacity to synthesize thyroid hormones have thyroxine (T4) levels of $35-70 \mathrm{nmol}$ in cord blood at birth, compared with $80-170 \mathrm{nmol}$ in normal newborns (7). So, despite the high levels of deiodinase activity, the fetus obtains a considerable proportion of its T4 from maternal circulation during late gestation, and it is likely to do so throughout gestation.

However, the observation that T4 reaches the human fetus in biologically relevant concentration (2) does not, in itself, demonstrate that T4 is affecting brain development. Likewise, the observation that thyroid hormone receptors are present in the human fetus by 8 weeks of gestation (the earliest time examined) does not in itself demonstrate that thyroid hormone affects fetal brain development $(8,9)$. To address this, epidemiological studies have identified an association between maternal thyroid status and neurological outcome of the offspring. For example, a recent report by Haddow et al. (10) associated maternal hypothyroxinemia with neurological outcome of the offspring. This group studied the children of women who had elevated thyrotropin (TSH) during the second trimester of pregnancy. They found that children whose mothers had elevated TSH at 16 weeks of gestation were significantly more likely to exhibit lower IQ $(<1$ SD below the mean). Previous work by Pop and colleagues in the Netherlands measured mothers' free T4 and thyroperoxidase antibody levels at 12 and 32 weeks of gestation and studied these mothers' children at 10 months of age. The strongest predictor of infant mental development was found to be the mothers' free T4 levels at 12 weeks of gestation (11). In addition, infants of women whose free T4 levels were low at both 12 and 32 weeks of gestation exhibited a poorer outcome than infants of women whose free T4 levels were low only at 12 weeks. These findings are supported by studies finding similar relationships, beginning with those of Evelyn Man in the 1960s and 1970s $(12,13)$.

Despite this growing clinical literature demonstrating an association between maternal thyroid status and the neurological outcome of the offspring, the experimental literature has lagged behind in offering a causal or mechanistic explanation for these findings. For example, the first report designed specifically to evaluate the effect on adult behavior of maternal thyroid hormone insufficiency during fetal development was published in 2000 (14). In the same year, Dowling et al. reported that thyroid hormone of maternal origin can selectively regulate the expression of several genes expressed in the ventricular zone of the fetal cortex (15). Thus, both clinical and experimental evidence supports the concept that thyroid hormone 
exerts important actions on the developing brain both in utero and postnatally. However, the experimental literature does not address the developmental events in the fetal brain affected by thyroid hormone or the mechanisms by which thyroid hormone effects are mediated.

\section{Relative sensitivity of the fetal brain to thyroid hormone insufficiency}

The significance of the work by Lavado-Autric et al. (1) lies in the combination of their relatively subtle manipulation of maternal thyroid status and their focus on specific neurodevelopmental events. Most studies, like those of Friedhoff et al. (14) and Dowling et al. (15), use thyroidectomy or treatment with potent goitrogens to produce severe hypothyroidism in the experimental animals. In contrast, Lavado-Autric et al. (1) used a lowiodine diet with or without potassium perchlorate to produce maternal hypothyroxinemia. Because almost $80 \%$ of circulating triiodothyronine (T3) is derived from peripheral deiodination of $\mathrm{T} 4$, and because $\mathrm{T} 3$ is the hormonally active form of thyroid hormone, it is generally considered that hypothyroxinemia - low T4 but normal T3 - might represent a physiologically compensated state. Supporting this concept, Lavado-Autric et al. show that their treatment did not affect litter size or weight, body weight, or postnatal growth measures. Thus, the animals might be compensating for low $\mathrm{T} 4$, perhaps by activating mechanisms to maintain circulating levels of T3.

To test whether maternal hypothyroxinemia can affect fetal brain development, the authors (1) took advantage of the fact that cortical neurons occupying different lamina are born at different times. Specifically, neurons born late in the process of cortical development migrate past cells born earlier to occupy more superficial layers of the cortex. The authors were able to track the final destination of cells born at specific developmental stages using timed exposure to BrdU, a chemical incorporated by dividing cells into their newly synthesized DNA. They found that a significant proportion of BrdU-labeled cells in the cortex of pups derived from hypothyroxinemic dams did not migrate far enough. When BrdU was administered early (gestational days 14-16), there was a decrease in the proportion of BrdU-labeled cells in deep cortical layers, and there was a concomitant increase in BrdU-labeled cells trapped in subcortical white matter. Follow-up studies demonstrated that these BrdUlabeled cells in white matter were indeed neurons, not glia. Likewise, when BrdU was administered later (gestational days 17-19), there was a decrease in the proportion of BrdUlabeled cells that migrated all the way to superficial layers and a concomitant increase in BrdU-labeled cells that were found in the deeper layers. Again, the cells did not migrate far enough. Moreover, this pattern was observed both in the primary somatosensory cortex and in specific subfields of the hippocampus.

\section{Conclusions}

It is important to recognize that the results of Lavado-Autric et al. (1) are not a case of delayed migration, but rather a case of a permanent alteration of cortical cytoarchitecture. The authors observed neurons in heterotopic positions at postnatal day 40. By this time, these cells would clearly be fully differentiated neurons. Thus, the effects of maternal hypothyroxinemia on the cytoarchitecture of the cortex and hippocampus are permanent. There is little information about the consequences that these defects in cytoarchitecture can have on the functioning of the adult rat brain, but it is very clear that migration defects in the human brain are associated with neurological deficits (16). Moreover, it is unclear how thyroid hormone produces the observed effects. The radial migration of cortical neurons is unique in that postmitotic neurons migrate along scaffolding provided by so-called radial glia (17). An important component of the regulation of radial migration in the cortex is the reelin-dab signaling system. Reelin is a large extracellular protein secreted by CajalRetzius neurons that bind to membrane receptors on migrating neurons, inducing the phosphorylation of disabled homolog 1 (Dab1) and triggering an intracellular signaling cascade that appears to be important in instructing cells in their proper destination (18). Reelin expression is reduced and Dab1 expression enhanced in the hypothyroid state (19). It is unclear whether the effects of thy- roid hormone on the Reelin-Dab1 system are direct, and whether this system plays a role in the results of Lavado-Autric et al. (1).

The finding that maternal hypothyroxinemia can permanently alter the cytoarchitecture of the cerebral cortex generates a number of important questions. Are lamina-specific synaptic connections affected by the "blurred" lamina? If these misplaced neurons are not properly connected to other fibers, why do they not undergo apoptosis? To what extent must maternal T4 levels decline before effects on cortical structure are observed? Considering that individual variation in circulating T4 is considerably smaller than the reference range for the population (20), what measures of thyroid function should be taken to best determine the health of the fetus? Considering that maternal hypothyroxinemia is estimated to be 150-200 times more prevalent than $\mathrm{CH}$, should mandatory screening for thyroid function be implemented for pregnant women, or for all women of reproductive age? Although many questions remain, the careful observations of Lavado-Autric et al. (1) represent an important contribution to a topic we know surprisingly little about.

1. Lavado-Autric, R., et al. 2003. Early maternal hypothyroxinemia alters histogenesis and cerebral cortex cytoarchitecture of the progeny. J. Clin. Invest. 111:1073-1082. doi:10.1172/JCI200316262.

2. Calvo, R.M., et al. 2002. Fetal tissues are exposed to biologically relevant free thyroxine concentrations during early phases of development. J. Clin. Endocrinol. Metab. 87:1768-1777.

3. Klein, R. 1980. History of congenital hypothyroidism. In Neonatal thyroid screening. G.N. Burrow and J.H. Dussault, editors. Raven Press. New York, New York, USA. 51-59.

4. Bernal, J. 2002. Action of thyroid hormone in brain. J. Endocrinol. Invest. 25:268-288.

5. Roti, E., Fang, S.-L., Green, K., Emerson, C.H., and Braverman, L.E. 1981. Human placenta is an active site of thyroxine and 3,3'5-triiodothyronine tyrosyl ring deiodination. J. Clin. Endocrinol Metab. 53:498-501.

6. Roti, E., Fang, S.-L., Green, K., Braverman, L.E., and Emerson, C.H. 1983. Inner ring deiodination of thyroxine and 3,5,3'-triiodothyronine by human fetal membranes. Am. J. Obstet. Gynecol. 147:788-792.

7. Vulsma, T., Gons, M.H., and de Vijlder, J.J. 1989 Maternal-fetal transfer of thyroxine in congenital hypothyroidism due to a total organification defect of thyroid agenesis. N. Engl. J. Med. 321:13-16

8. Bernal, J., and Pekonen, F. 1984. Ontogenesis of the nuclear 3,5,3'-triiodothyronine receptor in the human fetal brain. Endocrinology. 114:677-679.

9. Kilby, M.D., Gittoes, N., McCabe, C., Verhaeg, J. and Franklyn, J.A. 2000. Expression of thyroid receptor isoforms in the human fetal central nervous system and the effects of intrauterine growth restriction. Clin. Endocrinol. (Oxf.) 53:469-477.

10. Haddow, J.E., et al. 1999. Maternal thyroid defi- 
ciency during pregnancy and subsequent neuropsychological development of the child. N. Engl. J. Med. 341:549-555.

11. Pop, V.J., et al. 1999. Low maternal free thyroxine concentrations during early pregnancy are associated with impaired psychomotor development in infancy. Clin. Endocrinol. (Oxf.) 50:149-155.

12. Man, E.B. 1972. Thyroid function in pregnancy and infancy. Maternal hypothyroxinemia and retardation of progeny. CRC Crit. Rev. Clin. Lab. Sci. 3:203-225.

13. Man, E.B., Brown, J.F., and Serunian, S.A. 1991. Maternal hypothyroxinemia: psychoneurological deficits of progeny. Ann. Clin. Lab. Sci. 21:227-239.

14. Friedhoff, A.J., Miller, J.C., Armour, M.,
Schweitzer, J.W., and Mohan, S. 2000. Role of maternal biochemistry in fetal brain development: effect of maternal thyroidectomy on behaviour and biogenic amine metabolism in rat progeny. Int. J. Neuropsychopharmacol. 3:89-97.

15. Dowling, A.L.S., Martz, G.U., Leonard, J.L., and Zoeller, R.T. 2000. Acute changes in maternal thyroid hormone induce rapid and transient changes in specific gene expression in fetal rat brain. J. Neurosci. 20:2255-2265.

16. Sun, X.Z., et al. 2002. Normal and abnormal neuronal migration in the developing cerebral cortex. J. Med. Invest. 49:97-110.

17. Hatten, M.E. 2002. New directions in neurona migration. Science. 297:1660-1663.
18. Rice, D.S., and Curran, T. 2001. Role of the reelin signaling pathway in central nervous system development. Annu. Rev. Neurosci. 24:1005-1039.

19. Alvarez-Dolado, M., et al. 1999. Thyroid hormone regulates reelin and dab1 expression during brain development. J. Neurosci. 19:6979-6993.

20. Andersen, S., Pedersen, K.M., Bruun, N.H., and Laurberg, P. 2002. Narrow individual variations in serum $\mathrm{T}(4)$ and $\mathrm{T}(3)$ in normal subjects: a clue to the understanding of subclinical thyroid disease. J. Clin. Endocrinol. Metab. 87:1068-1072.

21. McConnell, S.K. 1995. Strategies for the generation of neuronal diversity in the developing central nervous system. J. Neurosci. 15:6987-6998. 